\title{
Evidence for critical role of Tie2/Ang1 interaction in metastatic oral cancer
}

\author{
DAISUKE KITAJIMA $^{1 *}$, ATSUSHI KASAMATSU ${ }^{2 *}$, DAI NAKASHIMA ${ }^{1}$, ISAO MIYAMOTO ${ }^{1}$, YASUSHI KIMURA ${ }^{3}$, \\ YOSUKE ENDO-SAKAMOTO ${ }^{2}$, MASASHI SHIIBA ${ }^{4}$, HIDEKI TANZAWA ${ }^{1,2}$ and KATSUHIRO UZAWA ${ }^{1,2}$ \\ ${ }^{1}$ Department of Oral Science, Graduate School of Medicine, Chiba University; ${ }^{2}$ Department of Dentistry and \\ Oral-Maxillofacial Surgery, Graduate School of Medicine, Chiba University Hospital, Chuo-ku, Chiba 260-8670; \\ ${ }^{3}$ Department of Oral and Maxillofacial Surgery, National Defense Medical College Hospital, Tokorozawa, Saitama 359-8513; \\ ${ }^{4}$ Department of Medical Oncology, Graduate School of Medicine, Chiba University, Chuo-ku, Chiba 260-8670, Japan
}

Received September 9, 2017; Accepted December 14, 2017

DOI: $10.3892 / \mathrm{ol} .2018 .8212$

\begin{abstract}
Angiopoietin-1 (Ang1) is a binding partner of endothelial cell-specific tyrosine-protein kinase receptor (Tie2), which serves important roles in vascular development and angiogenesis. Tie2 is closely associated with the metastasis of oral squamous cell carcinomas (OSCCs) however, little is known about the correlation between Tie 2 and Ang1. In the present study, the functional mechanisms of the Tie2/Ang1 interaction were investigated using Tie 2 overexpressed (oeTie2) OSCC cells and recombinant Ang1 protein. oeTie2 cells had increased cell-cell and cell-extracellular matrix adhesions compared with the control cells. Additionally, the adhesive activities increased following treatment with exogenous Ang1, indicating that Ang1 directly enhances Tie2 functions. In the clinical OSCC data from 10 cases positive for regional lymph node metastasis, all cases were negative for Tie2 expression and eight cases $(80 \%)$ were negative for Ang1 expression. These results suggest that Tie2 and Ang1 serve important roles in cancer metastasis and may be potential biomarkers and therapeutic targets for OSCC metastasis.
\end{abstract}

Correspondence to: Dr Atsushi Kasamatsu, Department of Dentistry and Oral-Maxillofacial Surgery, Graduate School of Medicine, Chiba University Hospital, 1-8-1 Inohana, Chuo-ku, Chiba 260-8670, Japan E-mail: kasamatsua@faculty.chiba-u.jp

Dr Katsuhiro Uzawa, Department of Oral Science, Graduate School of Medicine, Chiba University, 1-8-1 Inohana, Chuo-ku, Chiba 260-8670, Japan

E-mail: uzawak@faculty.chiba-u.jp

*Contributed equally

Key words: Ang1, Tie2, cell-cell adhesion, cell-extracellular matrix adhesion, oral squamous cell carcinoma, regional lymph node metastasis

\section{Introduction}

Cellular adhesion is controlled by adherent molecules in epithelial tissues, which are down-regulated in many cancers to promote transformation and might profoundly affect cellular migration and invasiveness (1-5). Since cancer metastasis decreases the patient survival rates, regional lymph node metastasis (RLNM) is one of the most adverse prognostic factors (6-12) for almost all cancers, including oral squamous cell carcinoma (OSCC). Therefore, elucidation of the molecular mechanisms involved in cancer metastasis clearly is needed to improve the prognosis $(6,13)$. We reported previously that endothelial cell-specific tyrosine-protein kinase receptor (Tie2) is related closely to OSCC metastasis using overexpressed Tie2 (oeTie2) cells and its neutralization technique (14).

Tie2 and its ligand, angiopoietin 1 (Ang1), are essential for vascular maturation and blood vessel remodeling during embryonic angiogenesis (15-25). Ang1 regulates endothelial cell survival (16), anti-inflammatory actions (26-28), and radiation-induced endothelial-cell damage (29). Ang1, produced by many types of cells, has been described as a transcriptionally regulated molecule in several tumors $(30,31)$. However, the Tie2/Ang1 interaction is poorly understood.

In the current study, we showed that the Tie2/Ang1 interaction promotes RLNM in OSCCs by controlling cellular adhesion. Thus, our results indicated that Tie2 and Ang1 are biomarkers for therapeutic targets in patients with OSCC.

\section{Materials and methods}

Ethics statement. The Ethics Committee of Chiba University approved our study protocol (approval no. 236), which was performed according to the tenets of the Declaration of Helsinki. All patients provided written informed consent.

oeTie 2 cells and tissue specimens. oeTie 2 cells, which were established in our previous study (14), were grown in Dulbecco's modified Eagle medium (DMEM) (Sigma-Aldrich; Merck KGaA, Darmstadt, Germany) supplemented with $10 \%$ fetal bovine serum (Sigma-Aldrich; Merck KGaA) and 50 units $/ \mathrm{ml}$ of penicillin and streptomycin (Sigma-Aldrich; Merck KGaA). 
We performed histopathological diagnosis of each OSCC sample according to the World Health Organization criteria at the Department of Pathology of Chiba University Hospital (32). The clinicopathological stages were determined based on the TNM classification of the International Union against Cancer (33). Twenty (10 cases each, RLNM-positive, RLNM-negative) pairs of primary OSCCs and patient-matched normal oral epithelia were obtained during surgical resections performed at Chiba University Hospital. The resected tissues were fixed in $20 \%$ buffered formaldehyde solution for pathologic diagnosis and immunohistochemistry (IHC).

mRNA expression analysis. Total RNA was isolated using TRIzol Reagent (Invitrogen; Thermo Fisher Scientific, Inc., Waltham, MA, USA), according to the manufacturer's instructions. cDNA was generated from $5 \mu \mathrm{g}$ of total RNA using Ready-To-Go You-Prime First-Strand Beads (GE Healthcare Life Sciences, Little Chalfont, UK) and oligo (dT) primers (Hokkaido System Science Co., Ltd., Sapporo, Japan). As described previously (14), real-time quantitative reverse transcriptase-polymerase chain reaction (qRT-PCR) was performed using the LightCycler 480 apparatus (Roche Diagnostics GmbH, Mannheim, Germany). Primers were designed using the Universal Probe Library Assay Design Center (http://lifescience.roche.com/), which specifies the most suitable set. The primer sequences used for qRT-PCR were: Tie2, forward, 5'-CCCCTATGGGTGTTCCTGT-3'; reverse, 5'-GCTTACAATCTGGCCCGTAA-3'; and probe, no. 10; and glyceraldehyde-3-phosphate dehydrogenase (GAPDH), forward, 5'-AACATCATCCCTGCCTCTACT GG-3'; reverse, 5'-TTGAAGTCAGAGGAGACCACTG-3'; and probe, no. 61 . The transcript amount was estimated from the respective standard curves and normalized to the GAPDH transcript amount determined in corresponding samples. All samples were analyzed in triplicate, and three independent preparations of RNA were analyzed from the cells.

Immunoblot analysis. The cells were washed twice with cold phosphate-buffered saline (PBS) and centrifuged briefly. The cellular pellets were incubated at $4^{\circ} \mathrm{C}$ for $30 \mathrm{~min}$ in a lysis buffer (7 M urea, $2 \mathrm{M}$ thiourea, $4 \%$ (w/v) CHAPS, and $10 \mathrm{mM}$ Tris). The protein concentration was measured using a commercial Bradford reagent (Bio-Rad Laboratories, Inc., Hercules, CA, USA). Immunoblot analysis was performed as described previously $(14,34-37)$. Briefly, protein extracts $(20 \mu \mathrm{g})$ were electrophoresed on 4-12\% Bis-Tris gel (Invitrogen; Thermo Fisher Scientific,Inc.), transferred to poly vinylidene fluoride membranes (Invitrogen; Thermo Fisher Scientific, Inc.), and blocked for $1 \mathrm{~h}$ at room temperature in Blocking One (Nacalai Tesque Inc., Kyoto, Japan). The membranes were washed three times with $0.1 \%$ Tween-20 in Tris-buffered saline (TBS-T) and incubated with affinity-purified rabbit anti-Tie2 polyclonal antibody (Santa Cruz Biotechnology, Inc., Dallas, TX, USA) or mouse anti-GAPDH monoclonal antibody (Santa Cruz Biotechnology, Inc.) overnight at $4^{\circ} \mathrm{C}$. The membranes were washed with TBS-T and incubated with horseradish peroxidase-conjugated anti-rabbit or anti-mouse IgG as a secondary antibody (Promega Corporation, Madison, WI, USA) for $1 \mathrm{~h}$ at room temperature. Finally, the membranes were detected using Super-Signal West Pico Chemiluminescent substrate (Thermo Fisher Scientific, Inc.), and immunoblot analyses were visualized by exposing the membranes to the ChemiDoc XRS system (Bio-Rad Laboratories, Inc.). The signal intensities were quantitated using Image Lab software (BioRad Laboratories, Inc.). Densitometric Tie2 protein data were normalized to the GAPDH protein levels.

Cellular aggregation assay. To investigate the effect of Tie2 and cartilage oligomeric matrix protein, Ang1, a ligand for Tie2, on cell-cell adhesion, we performed cellular aggregation assays as described previously $(38,39)$. The oeTie 2 and Mock cells were incubated for $30 \mathrm{~min}$ at $37^{\circ} \mathrm{C}$ in PBS containing $1 \mathrm{mM}$ ethylenediaminetetraacetic acid, detached by gentle agitation, washed, and mechanically dissociated to obtain a single-cell suspension. The $3 \times 10^{5}$ single cells in $1 \mathrm{ml}$ of the serum-free DMEM were transferred to 12 -well tissue culture plates and rotated at 60 rotations/min for $30 \mathrm{~min}$ at room temperature supplemented with and without human Ang1 (1 $\mu \mathrm{g} / \mathrm{ml})(\mathrm{R} \& \mathrm{D}$ Systems, Inc., Minneapolis, MN, USA) or heat-inactivated Ang1 $(1 \mu \mathrm{g} / \mathrm{ml})$. Three random fields, each containing 200 cells, were viewed at $\times 200$ magnification for the presence of single and adherent cells. The percentage of adherent cells was calculated for each field and averaged $(38,39)$.

Cellular adhesion assay. An adhesion assay was performed as described previously $(14,40)$. Briefly, the cells were seeded in collagen I-coated 96-well plates, incubated for $1 \mathrm{~h}$ at $37^{\circ} \mathrm{C}$ at a density of $2 \times 10^{4}$ cells/well, and incubated for $1 \mathrm{~h}$ in DMEM, washed once with PBS, fixed in methanol, stained with crystal violet, and photographed. The numbers of the stained cells were measured using a microplate spectrophotometer (absorbance at $540 \mathrm{~nm}$ and at $405 \mathrm{~nm}$ to subtract the background). Before the adhesion assay, collagen I-coated 96-well plates were treated with and without Ang1 $(1 \mu \mathrm{g} / \mathrm{ml})$ or heat-inactivated Ang1 $(1 \mu \mathrm{g} / \mathrm{ml})$ for $1 \mathrm{~h}$, and the assay was performed.

Multiplex IHC. Multiplex IHC was performed on 4- $\mu \mathrm{m}$ sections of paraffin-embedded specimens using rabbit anti-Tie2 polyclonal antibody (Santa Cruz Biotechnology, Inc.) and mouse anti-Ang1 polyclonal antibody (LifeSpan BioSciences, Inc., Seattle, WA, USA). Briefly, after deparaffinization and hydration, the endogenous peroxidase activity was quenched by a 3 -min incubation in a mixture of $0.3 \%$ hydrogen peroxide solution in $100 \%$ methanol. The sections were blocked for $2 \mathrm{~h}$ at room temperature with $1.5 \%$ blocking serum (Santa Cruz Biotechnology, Inc.) in PBS before reaction with the anti-Tie2 and anti-Ang1 antibodies at $4^{\circ} \mathrm{C}$ in a moist chamber overnight. For all washing steps, $0.1 \%$ Tween-20 in PBS was used. After primary antibody incubations, the Envision G/2 Double Stain System, Rabbit/Mouse (DAB+/Permanent Red) (Agilent Technologies, Inc., Santa Clara, CA, USA) was used according to the manufacturer's instructions. The slides were counterstained lightly with hematoxylin, dehydrated with ethanol, cleaned with xylene, and mounted. As a negative control, triplicate sections were immunostained without exposure to primary antibodies, which confirmed the staining specificity. To quantify the status of the Tie2 and Ang1 protein expression levels, we used the IHC scoring systems described previously $(14,41-45)$. The mean percentages of positively stained cells were determined in at least three random fields at x400 magnification in each section. 
A

B
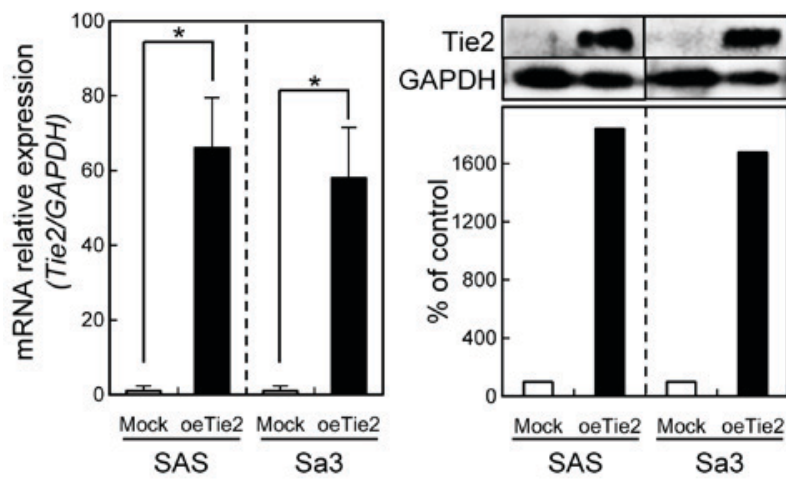

C
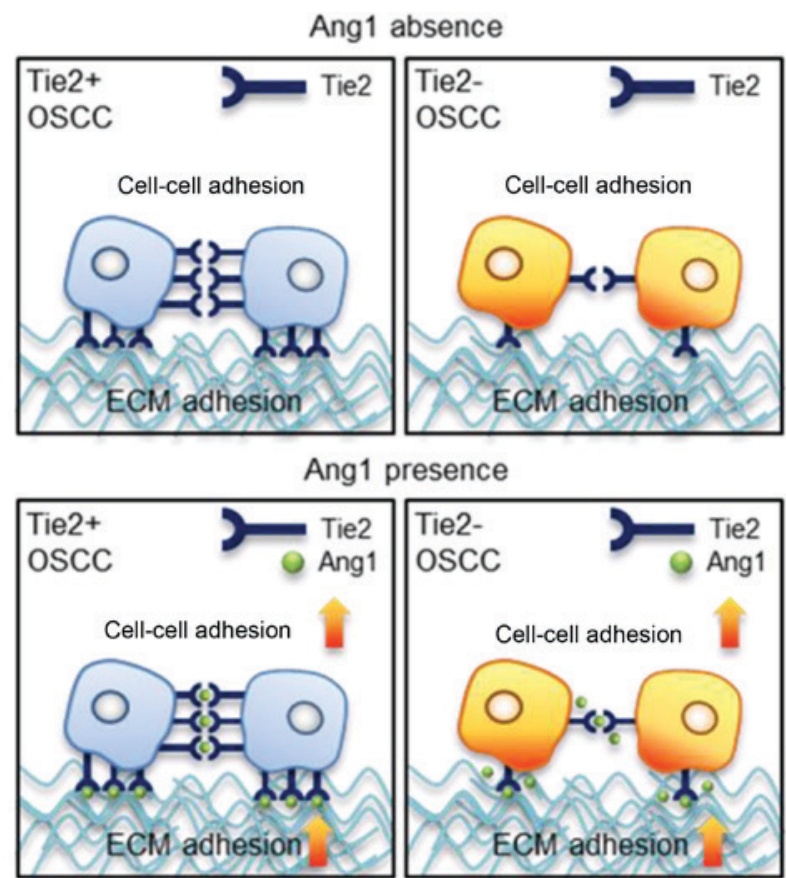

Figure 1. Expression level of Tie2 in its overexpressed cells. Significant ( ${ }^{*} \mathrm{P}<0.05$, Mann-Whitney U-test) up-regulation of (A) Tie2 mRNA and (B) protein are observed in oeTie2 cells compared with Mock cells (SAS and $\mathrm{Sa} 3$ cells) by RT-qPCR and immunoblot analyses. The Tie 2 expression data are normalized to the GAPDH expression levels. The protein values are expressed as a percentage of the Mock cells. Data are expressed as the mean \pm standard error of the mean (SEM) of triplicate results form independent three experiments. (C) Schematic representation of Tie2 and Ang1 functions for cell-cell and cell-ECM adhesions. Overexpression of Tie2 and exogenous Ang1 are related closely to cell-cell and cell-ECM adhesions in the cancer cells.

Statistical analysis. To compare the Tie2 expression levels and the cell-cell and cell-extracellular matrix (ECM) adhesive capacities, statistical significance was evaluated using the Mann-Whitney U-test. $\mathrm{P}<0.05$ was considered to indicate a statistically significant difference.

\section{Results}

Expression level of Tie2 in its overexpressed cells. Since frequent down-regulation of Tie2 was observed in OSCC in vitro and in vivo, we previously established oeTie2 cells derived from two OSCC cell lines, SAS and Sa3 (14). To confirm the expression level of Tie2 in the oeTie2 cells, we performed qRT-PCR
A

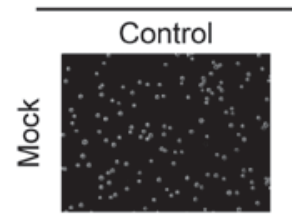

Control
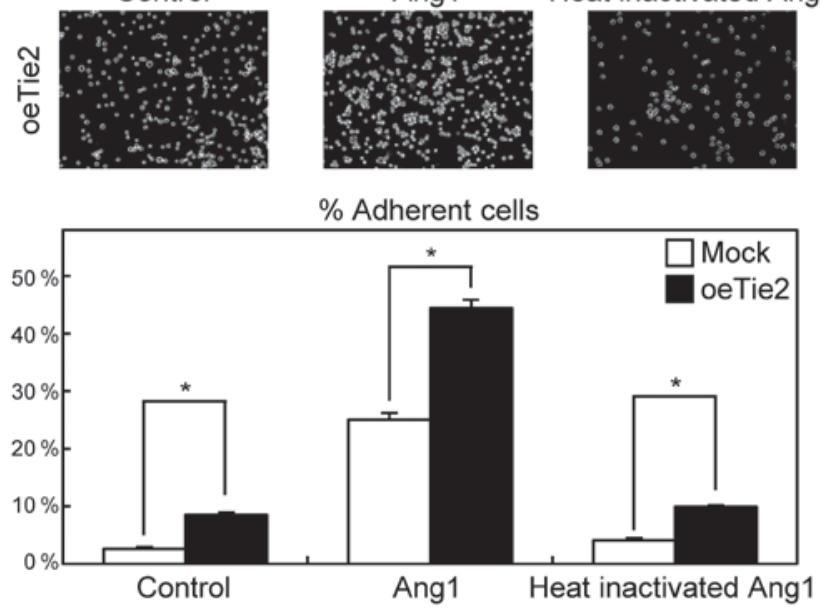

B

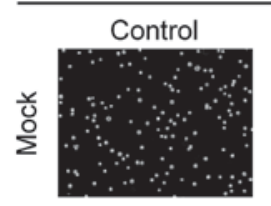

Control
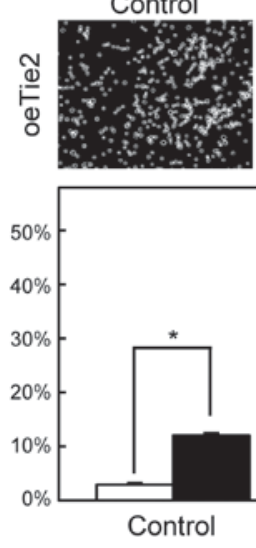

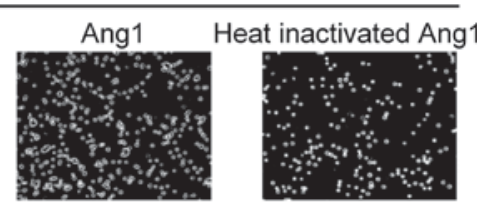

Ang1
Heat inactivated Ang1
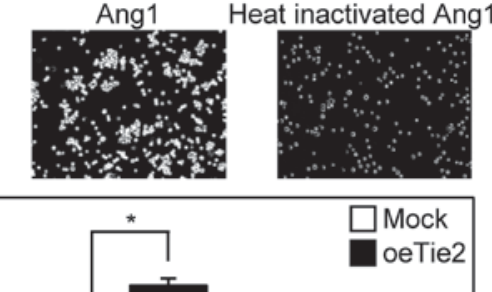

oeTie2

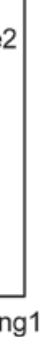

SAS

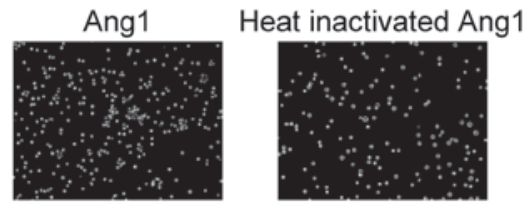

Ang1

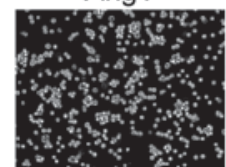

Heat inactivated Ang1

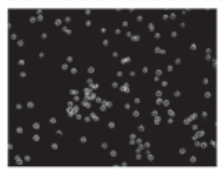

$\because \cdots \cdots$

$\%$ Adherent cells

Sa3
Figure 2. Cellular aggregation assay of Tie2 overexpressed cells. To evaluate the effects of Tie2 and Ang1 on (A) SAS and (B) Sa3 cell-cell adhesion activity, we performed a cellular aggregation assay. (Control) The cell-cell adhesion activity of oeTie 2 cells is increased significantly (" $\mathrm{P}<0.05$, Mann-Whitney U-test) compared with Mock cells. (Ang1/heat-inactivated Ang1) After treatment with Ang1, the numbers of aggregated cells increased dramatically ( $\mathrm{P}<0.05$, Mann-Whitney U-test) compared with the control cells and cells treated with heat-inactivated Ang1. Data are expressed as the mean \pm standard error of the mean (SEM) of triplicate results form independent three experiments.

and immunoblot analyses. Consistent with our previous study, the Tie2 mRNA and protein expression levels in oeTie2 cells were significantly $(\mathrm{P}<0.05)$ higher than that in the Mock cells (Fig. 1A and B). Our previous study also showed that Tie2 plays an important role in cellular adhesion. In the current study, we hypothesized that not only Tie2 but also Ang1, the specific ligand for Tie2, regulate cell-cell and cell-ECM interactions (Fig. 1C). 
A

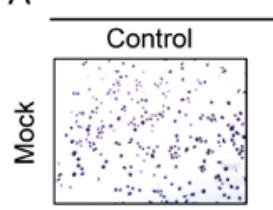

Control

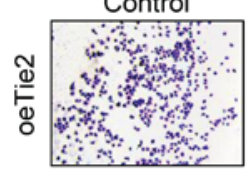

Cell adhesion (absorbance 540nm)

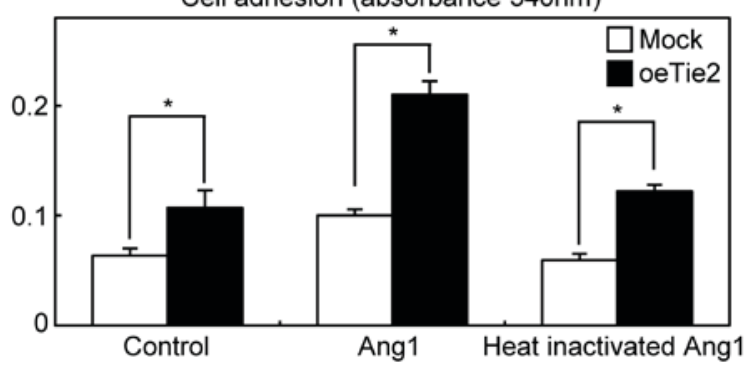

B

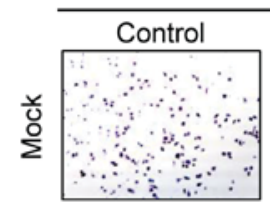

Control

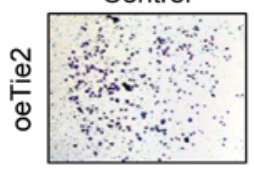

Cell adhesion (absorbance $540 \mathrm{~nm}$ )

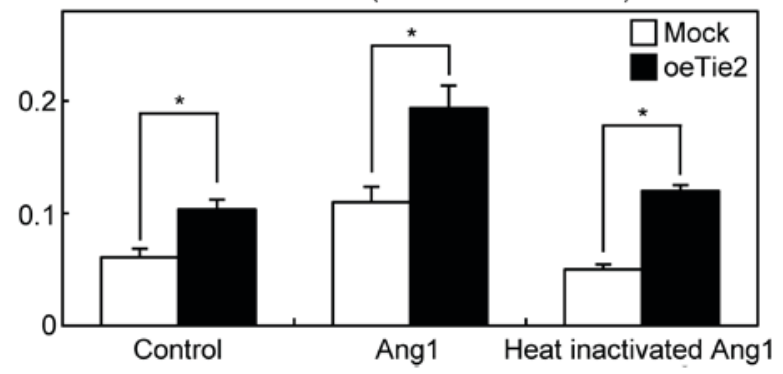

Figure 3. Cellular adhesion assay of Tie2 overexpressed cells. To evaluate the cell-ECM adhesion ability, (A) SAS and (B) Sa3 oeTie2 and Mock cells are seeded on collagen I-coated 96 -well plates at a density of $2 \times 10^{4}$ cells/well and allowed to adhere for $1 \mathrm{~h}$. After crystal violet staining, the numbers of stained cells are measured using a microplate spectrophotometer (absorbance at 540 and $405 \mathrm{~nm}$ to subtract background). (Control) The cell-ECM adhesion in the oeTie 2 cells is increased significantly $\left({ }^{*} \mathrm{P}<0.05\right.$, Mann-Whitney U-test) compared with Mock cells. (Ang1/heat-inactivated Ang1) The cell-ECM adhesion ability of the oeTie2 cells treated with Ang1 is increased significantly ( ${ }^{*} \mathrm{P}<0.05$, Mann-Whitney U-test) compared with the control cells and cells treated with heat-inactivated Ang1. Data are expressed as the mean \pm standard error of the mean (SEM) of triplicate results form independent three experiments.

Functional analyses of oeTie 2 cells. To evaluate the effect of Tie 2 overexpression on cell-cell adhesion activity, we performed the cellular aggregation assay. The cell-cell adhesion activity of oeTie2 cells increased significantly $(\mathrm{P}<0.05)$ compared with Mock cells (control) (Fig. 2A and B). We
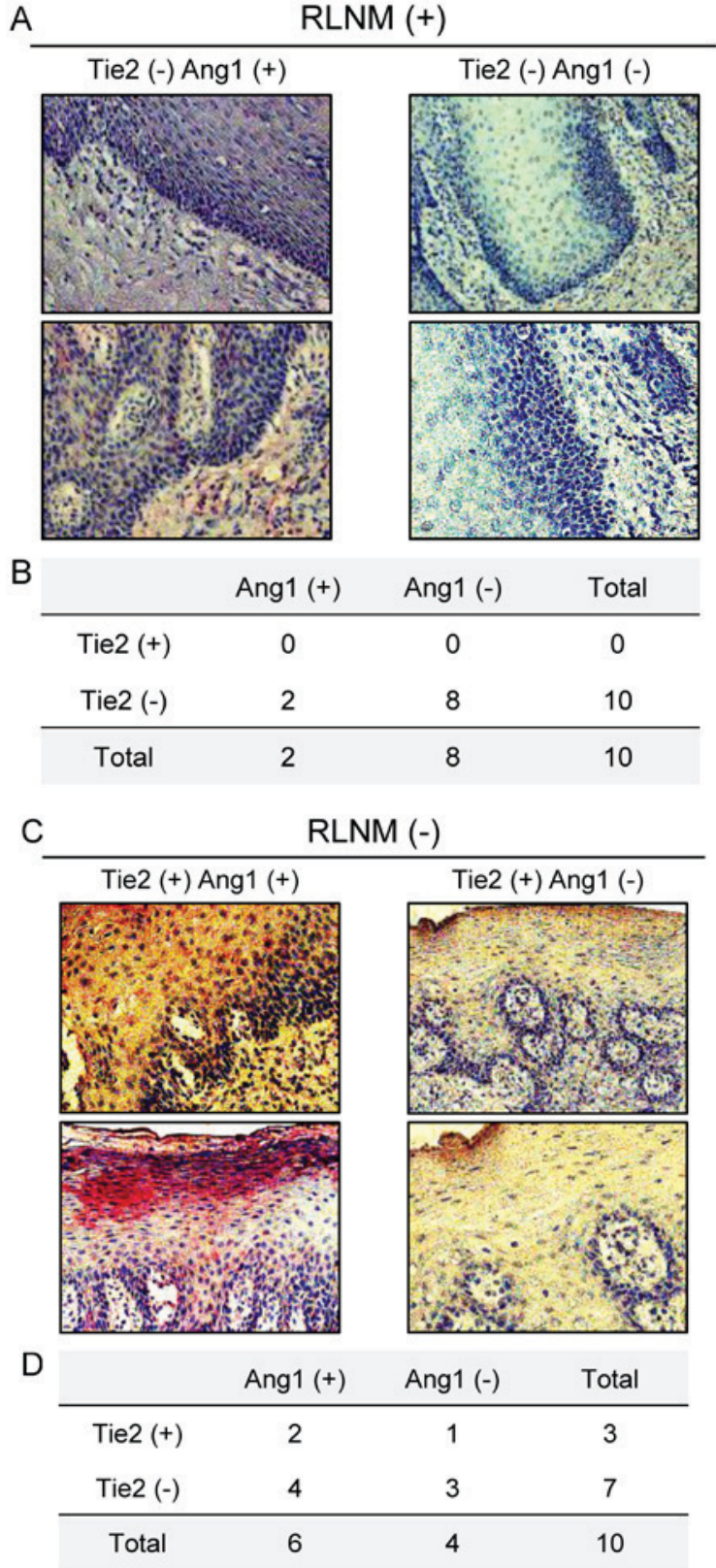

Figure 4. Evaluation of Tie2 and Ang1 expression levels in primary OSCCs and the clinical correlations with RLNM. Representative multiplex IHC results for Tie2 and Ang1 proteins in the RLNM-positive and -negative groups. (A, C) All RLNM-positive cases have weak immunoreactivity for Tie2. In addition, eight $(80 \%)$ of the 10 cases have weak immunoreactivity for Ang1. (B, D) Three RLNM-negative cases have strong immunoreactions for Tie2. Six (60\%) RLNM-negative cases have strong immunoreactivity for Ang1. Original magnification, x200.

then examined whether Ang1 regulates cell-cell adhesion activity. After treatment with Ang1, the number of aggregated cells increased dramatically compared with control cells and the cells treated with heat-inactivated Ang1 (Ang1 and heat-inactivated Ang1) (Fig. 2A, B).

We then performed a cellular adhesion assay to determine the biologic effects of Tie2 and Ang1 on cell-ECM interactions. The cell-ECM adhesion in the oeTie2 cells increased significantly $(\mathrm{P}<0.05)$ compared with Mock cells (control) (Fig. 3A and B). In addition, the cell-ECM adhesion activity of the cells treated with Ang1 increased significantly compared with the control cells and the cells treated with heat-inactivated Ang1 (Ang1 and 
heat-inactivated Ang1) (Fig. 3A and B), suggesting that not only Tie2 but also Ang1 might be critical molecules for cell-cell and cell-ECM adhesions.

Evaluation of Tie2 and Angl expression levels in primary OSCCs and the clinical correlations with RLNM. We analyzed the Tie2 and Ang1 protein expression levels in 20 cases of primary OSCCs, RLNM-positive ( $n=10$ cases) and RLNM-negative ( $n=10$ cases), using the IHC scoring system. Representative IHC results for the Tie2 and Ang1 proteins in primary OSCC are shown in Fig. 4A and B. In the RLNM-positive cases, all cases $(100 \%)$ were Tie2 negative, and eight $(80 \%)$ cases were Ang1 negative (double negative expression, $8 / 10$ cases), whereas three (30\%) of the 10 RLNM-negative cases were negative for both Tie2 and Ang1 (Fig. 4C and D).

\section{Discussion}

In addition to our previous finding that Tie 2 is in part a key modulator of OSCC tumor adhesion and invasion (14), the current findings indicated that the ligand of Tie2, Ang1, enhances the Tie 2 functions in OSCC progression. Although cancer cells show that Tie 2 is related closely to cancer metastasis $(14,46,47)$, little is known about Ang1 function in cancer research.

Ang1 is thought to support endothelial cell adhesion and vascular integrity while inhibiting vascular permeability $(18,19,48,49)$. Ang1 also induces phosphorylation of Tie 2 and promotes endothelial cell migration and survival (23,50-52). The Tie2/Ang1 signaling pathway is thought to regulate proliferation and osteogenic differentiation of mesenchymal stem cells through activation of the p38 MAPK and Akt pathways $(53,54)$. The Tie2/Ang1 interaction has different functions during angiogenesis and differentiation, suggesting that the Tie2/Ang1 signaling pathway differs at the molecular level in several types of cells. Since Kim et al reported a novel Ang1 function as a cell primer (55), we speculated that Ang1 increases cell-cell and cell-ECM adhesion activities through the Tie2/Ang1 interaction (Fig. 1C). Consistent with our hypothesis, patients with OSCC with low expression of Tie 2 and Ang1 have high risk for RLNM (Fig. 4).

In conclusion, these data provide new insight that the Tie2/Ang1 interaction seems to have complex regulatory mechanisms, especially considering our finding that the Tie2/Ang1 interaction controls critical behaviors in metastatic OSCCs. While further studies using large cohort specimens are needed to study the Tie2/Ang1 interaction, the current data suggested that the Tie2/Ang1 interaction plays an important role in cellular adhesion and might be a potential biomarker for RLNM in OSCCs.

\section{Acknowledgements}

The authors would like to thank Ms. Lynda C. Charters for editing this manuscript.

\section{References}

1. Jamora $\mathrm{C}$ and Fuchs E: Intercellular adhesion, signalling and the cytoskeleton. Nat Cell Biol 4: E101-E108, 2002.

2. Green KJ and Simpson CL: Desmosomes: New perspectives on a classic. J Invest Dermatol 127: 2499-2515, 2007.
3. Dusek RL and Attardi LD: Desmosomes: New perpetrators in tumour suppression. Nat Rev Cancer 11: 317-323, 2011.

4. South AP, Wan H, Stone MG, Dopping-Hepenstal PJ, Purkis PE, Marshall JF, Leigh IM, Eady RA, Hart IR and McGrath JA: Lack of plakophilin 1 increases keratinocyte migration and reduces desmosome stability. J Cell Sci 116: 3303-3314, 2003.

5. Yin T and Green KJ: Regulation of desmosome assembly and adhesion. Semin Cell Dev Biol 15: 665-677, 2004.

6. Takes RP: Staging of the neck in patients with head and neck squamous cell cancer: Imaging techniques and biomarkers. Oral Oncol 40: 656-667, 2004

7. Karatzanis AD, Waldfahrer F, Psychogios G, Hornung J, Zenk J, Velegrakis GA and Iro H: Resection margins and other prognostic factors regarding surgically treated glottic carcinomas. J Surg Oncol 101: 131-136, 2010.

8. Fan S, Tang QL, Lin YJ, Chen WL, Li JS, Huang ZQ, Yang ZH, Wang YY, Zhang DM, Wang HJ, et al: A review of clinical and histological parameters associated with contralateral neck metastases in oral squamous cell carcinoma. Int J Oral Sci 3: 180-191, 2011.

9. Lea J, Bachar G, Sawka AM, Lakra DC, Gilbert RW, Irish JC, Brown DH, Gullane PJ and Goldstein DP: Metastases to level IIb in squamous cell carcinoma of the oral cavity: A systematic review and meta-analysis. Head Neck 32: 184-190, 2010.

10. Okura M, Aikawa T, Sawai NY, Iida S and Kogo M: Decision analysis and treatment threshold in a management for the N0 neck of the oral cavity carcinoma. Oral Oncol 45: 908-911, 2009.

11. Greenberg JS, Fowler R, Gomez J, Mo V, Roberts D, El Naggar AK and Myers JN: Extent of extracapsular spread: A critical prognosticator in oral tongue cancer. Cancer 97: 1464-1470, 2003

12. Sano D and Myers JN: Metastasis of squamous cell carcinoma of the oral tongue. Cancer Metastasis Rev 26: 645-662, 2007.

13. Casiglia J and Woo SB: A comprehensive review of oral cancer. Gen Dent 49: 72-82, 2001

14. Kitajima D, Kasamatsu A, Nakashima D, Miyamoto I, Kimura Y, Saito T, Suzuki T, Endo-Sakamoto Y, Shiiba M, Tanzawa H and Uzawa K: Tie2 regulates tumor metastasis of oral squamous cell carcinomas. J Cancer 7: 600-607, 2016.

15. Dumont DJ, Gradwohl G, Fong GH, Puri MC, Gertsenstein M, Auerbach A and Breitman ML: Dominant-negative and targeted null mutations in the endothelial receptor tyrosine kinase, tek, reveal a critical role in vasculogenesis of the embryo. Genes Dev 8: 1897-1909, 1994

16. Suri C, Jones PF, Patan S, Bartunkova S, Maisonpierre PC, Davis S, Sato TN and Yancopoulos GD: Requisite role of angiopoietin-1, a ligand for the TIE2 receptor, during embryonic angiogenesis. Cell 87: 1171-1180, 1996.

17. Sato TN, Tozawa Y, Deutsch U, Wolburg-Buchholz K, Fujiwara Y, Gendron-Maguire M, Gridley T, Wolburg H, Risau W and Qin Y: Distinct roles of the receptor tyrosine kinases Tie-1 and Tie-2 in blood vessel formation. Nature 376: 70-74, 1995.

18. Yancopoulos GD, Davis S, Gale NW, Rudge JS, Wiegand SJ and Holash J: Vascular-specific growth factors and blood vessel formation. Nature 407: 242-248, 2000.

19. Peters KG, Kontos CD, Lin PC, Wong AL, Rao P, Huang L, Dewhirst MW and Sankar S: Functional significance of Tie2 signaling in the adult vasculature. Recent Prog Horm Res 59: $51-71,2004$

20. Brindle NP, Saharinen P and Alitalo K: Signaling and functions of angiopoietin-1 in vascular protection. Circ Res 98: 1014-1023, 2006.

21. Eklund L and Olsen BR: Tie receptors and their angiopoietin ligands are context-dependent regulators of vascular remodeling. Exp Cell Res 312: 630-641, 2006.

22. Pfaff D, Fiedler U and Augustin HG: Emerging roles of the Angiopoietin-Tie and the ephrin-Eph systems as regulators of cell trafficking. J Leukoc Biol 80: 719-726, 2006.

23. Davis S, Aldrich TH, Jones PF, Acheson A, Compton DL, Jain V, Ryan TE, Bruno J, Radziejewski C, Maisonpierre PC and Yancopoulos GD: Isolation of angiopoietin-1, a ligand for the TIE2 receptor, by secretion-trap expression cloning. Cell 87: 1161-1169, 1996.

24. Jones N, Iljin K, Dumont DJ and Alitalo K: Tie receptors: New modulators of angiogenic and lymphangiogenic responses. Nat Rev Mol Cell Biol 2: 257-267, 2001.

25. Maisonpierre PC, Suri C, Jones PF, Bartunkova S, Wiegand SJ, Radziejewski C, Compton D, McClain J, Aldrich TH, Papadopoulos N, et al: Angiopoietin-2, a natural antagonist for Tie2 that disrupts in vivo angiogenesis. Science 277: 55-60, 1997. 
26. Gamble JR, Drew J, Trezise L, Underwood A, Parsons M, Kasminkas L, Rudge J, Yancopoulos G and Vadas MA: Angiopoietin-1 is an antipermeability and anti-inflammatory agent in vitro and targets cell junctions. Circ Res 87: 603-607, 2000.

27. Jeon BH, Khanday F, Deshpande S, Haile A, Ozaki M and Irani K: Tie-ing the antiinflammatory effect of angiopoietin-1 to inhibition of NF-kappaB. Circ Res 92: 586-588, 2003.

28. Ramsauer M and D'Amore PA: Getting Tie(2)d up in angiogenesis. J Clin Invest 110: 1615-1617, 2002.

29. Cho CH, Kammerer RA, Lee HJ, Yasunaga K, Kim KT, Choi HH, Kim W, Kim SH, Park SK, Lee GM and Koh GY: Designed angiopoietin-1 variant, COMP-Ang1, protects against radiation-induced endothelial cell apoptosis. Proc Natl Acad Sci USA 101: 5553-5558, 2004.

30. Stratmann A, Risau W and Plate KH: Cell type-specific expression of angiopoietin-1 and angiopoietin-2 suggests a role in glioblastoma angiogenesis. Am J Pathol 153: 1459-1466, 1998.

31. Sugimachi K, Tanaka S, Taguchi K, Aishima S, Shimada M and Tsuneyoshi M: Angiopoietin switching regulates angiogenesis and progression of human hepatocellular carcinoma. J Clin Pathol 56: 854-860, 2003

32. Pindborg JJ, Reichart PA, Smith CJ and van der Waal I: Histological typing of cancer and precancer of the oral mucosa. In: World Health Organization classification of tumours. 2nd edition. Springer-Verlag Berlin Heidelberg.

33. Sobin LH, Gospodarowicz MK and Wittekind C: TNM classification of malignant tumors. 7th edition. New York: Wiley-Liss, 2009.

34. Minakawa Y, Kasamatsu A, Koike H, Higo M, Nakashima D, Kouzu Y, Sakamoto Y, Ogawara K, Shiiba M, Tanzawa H and Uzawa K: Kinesin family member 4A: A potential predictor for progression of human oral cancer. PLoS One 8: e85951, 2013.

35. Yamatoji M, Kasamatsu A, Kouzu Y, Koike H, Sakamoto Y, Ogawara K, Shiiba M, Tanzawa H and Uzawa K: Dermatopontin: A potential predictor for metastasis of human oral cancer. Int J Cancer 130: 2903-2911, 2012.

36. Uchida F, Uzawa K, Kasamatsu A, Takatori H, Sakamoto Y, Ogawara K, Shiiba M, Tanzawa H and Bukawa H: Overexpression of cell cycle regulator CDCA3 promotes oral cancer progression by enhancing cell proliferation with prevention of G1 phase arrest. BMC Cancer 12: 321, 2012.

37. Unozawa M, Kasamatsu A, Higo M, Fukumoto C, Koyama T, Sakazume T, Nakashima D, Ogawara K, Yokoe H, Shiiba M, et al: Cavin-2 in oral cancer: A potential predictor for tumor progression. Mol Carcinog 55: 1037-1047, 2016

38. Ramanathan R, Wilkemeyer MF, Mittal B, Perides G and Charness ME: Alcohol inhibits cell-cell adhesion mediated by human L1. J Cell Biol 133: 381-390, 1996.

39. Tripathi V, Popescu NC and Zimonjic DB: DLC1 induces expression of E-cadherin in prostate cancer cells through Rho pathway and suppresses invasion. Oncogene 33: 724-733, 2014.

40. Kasamatsu A, Uzawa K, Nakashima D, Koike H, Shiiba M, Bukawa $\mathrm{H}$, Yokoe $\mathrm{H}$ and Tanzawa $\mathrm{H}$ : Galectin-9 as a regulator of cellular adhesion in human oral squamous cell carcinoma cell lines. Int J Mol Med 16: 269-273, 2005.

41. Endo Y, Uzawa K, Mochida Y, Shiiba M, Bukawa H, Yokoe H and Tanzawa H: Sarcoendoplasmic reticulum $\mathrm{Ca}(2+)$ ATPase type 2 downregulated in human oral squamous cell carcinoma. Int J Cancer 110: 225-231, 2004.

42. Lombardi DP, Geradts J, Foley JF, Chiao C, Lamb PW and Barrett JC: Loss of KAI1 expression in the progression of colorectal cancer. Cancer Res 59: 5724-5731, 1999.
43. Shimada K, Uzawa K, Kato M, Endo Y, Shiiba M, Bukawa H, Yokoe H, Seki N and Tanzawa H: Aberrant expression of RAB1A in human tongue cancer. Br J Cancer 92: 1915-1921, 2005.

44. Baba T, Sakamoto Y, Kasamatsu A, Minakawa Y, Yokota S, Higo M, Yokoe H, Ogawara K, Shiiba M, Tanzawa $H$ and Uzawa K: Persephin: A potential key component in human oral cancer progression through the RET receptor tyrosine kinase-mitogen-activated protein kinase signaling pathway. Mol Carcinog 54: 608-617, 2015.

45. Ishige S, Kasamatsu A, Ogoshi K, Saito Y, Usukura K, Yokoe H, Kouzu Y, Koike H, Sakamoto Y, Ogawara K, et al: Decreased expression of kallikrein-related peptidase 13: Possible contribution to metastasis of human oral cancer. Mol Carcinog 53: 557-565, 2014.

46. Saharinen P, Eklund L, Miettinen J, Wirkkala R, Anisimov A, Winderlich M, Nottebaum A, Vestweber D, Deutsch U, Koh GY, et al: Angiopoietins assemble distinct Tie2 signalling complexes in endothelial cell-cell and cell-matrix contacts. Nat Cell Biol 10: 527-537, 2008

47. Buehler D, Rush P, Hasenstein JR, Rice SR, Hafez GR, Longley BJ and Kozak KR: Expression of angiopoietin-TIE system components in angiosarcoma. Mod Pathol 26: 1032-1040, 2013.

48. Wong AL, Haroon ZA, Werner S, Dewhirst MW, Greenberg CS and Peters KG: Tie2 expression and phosphorylation in angiogenic and quiescent adult tissues. Circ Res 81: 567-574, 1997.

49. Thurston G, Suri C, Smith K, McClain J, Sato TN, Yancopoulos GD and McDonald DM: Leakage-resistant blood vessels in mice transgenically overexpressing angiopoietin-1. Science 286: 2511-2514, 1999.

50. Koblizek TI, Weiss C, Yancopoulos GD, Deutsch U and Risau W: Angiopoietin-1 induces sprouting angiogenesis in vitro. Curr Biol 8: 529-532, 1998

51. Papapetropoulos A, García-Cardeña G, Dengler TJ, Maisonpierre PC, Yancopoulos GD and Sessa WC: Direct actions of angiopoietin-1 on human endothelium: Evidence for network stabilization, cell survival, and interaction with other angiogenic grow th factors. Lab Invest 79: 213-223, 1999.

52. Saharinen P, Kerkelä K, Ekman N, Marron M, Brindle N, Lee GM, Augustin H, Koh GY and Alitalo K: Multiple angiopoietin recombinant proteins activate the Tiel receptor tyrosine kinase and promote its interaction with Tie2. J Cell Biol 169: 239-243, 2005

53. Kim S, Lee JC, Cho ES and Kwon J: COMP-Ang1 promotes chondrogenic and osteogenic differentiation of multipotent mesenchymal stem cells through the Ang1/Tie2 signaling pathway. J Orthop Res 31: 1920-1928, 2013.

54. Kook SH, Lim SS, Cho ES, Lee YH, Han SK, Lee KY, Kwon J, Hwang JW, Bae CH, Seo YK and Lee JC: COMP-angiopoietin 1 increases proliferation, differentiation, and migration of stem-like cells through Tie-2-mediated activation of p38 MAPK and PI3K/Akt signal transduction pathways. Biochem Biophys Res Commun 455: 371-377, 2014.

55. Kim MS, Lee CS, Hur J, Cho HJ, Jun SI, Kim TY, Lee SW, Suh JW, Park KW, Lee HY, et al: Priming with angiopoietin-1 augments the vasculogenic potential of the peripheral blood stem cells mobilized with granulocyte colony-stimulating factor through a novel Tie2/Ets-1 pathway. Circulation 120: 2240-2250, 2009 . 